\title{
Impact of Yoga on Postural Stability in Stroke
}

\section{Peter Altenburger $\mathbf{A}^{1,2^{*}}$, Arlene Schmid $\mathbf{A}^{3}$, Marieke Van Puymbroeck ${ }^{4}$ and Kristine Miller $\mathbf{K}^{1,5}$}

${ }^{1}$ Indiana University School of Health and Rehabilitation Sciences, Department of Physical Therapy, Indianapolis, IN, United States

${ }^{2}$ Indiana Center for Advanced Neurorehabilitation at Indiana University Health Neuroscience Center, United States

${ }^{3}$ Colorado State University, Department of Occupational Therapy, Ft. Collins, CO, United States

${ }^{4}$ Clemson University Department of Park, Recreation, and Tourism Management, Clemson, SC, United States

${ }^{5}$ Roudebush Veterans Administration (VA) Medical Center; Health Services Research and Development (HSR\&D) Center on Implementing Evidence-Based Practice, Indianapolis, IN, United States

*Corresponding author: Peter Altenburger, Department of Physical Therapy, Indiana University, 1140 W. Michigan St. CF326, Indianapolis, IN 46202, USA, Tel: 317-278-0703; E-mail: paltenbu@iu.edu

Rec date: Oct 29, 2015; Acc date: Feb 16, 2016; Pub date: Feb 22, 2016

Copyright: (c) 2016 Altenburger PA, et al. This is an open-access article distributed under the terms of the Creative Commons Attribution License, which permits unrestricted use, distribution, and reproduction in any medium, provided the original author and source are credited.

\begin{abstract}
Deficits in motor capacity following stroke poses a potential threat to postural stability. The purpose of the study was to assess the impact of yoga training on postural alignment, anticipatory postural adjustments, and compensatory postural adjustments in individuals with chronic stroke deficits. This study is a subset analysis from a prospective, randomized control trial using therapeutic yoga. Twenty one individuals with chronic motor deficits from stroke participated in an hour-long group yoga sessions twice a week for 8 weeks focusing on progressively challenging postures, breathing, and meditation in sitting, standing, and supine positions. Postural symmetry, compensatory postural adjustment, and anticipatory postural adjustment from the NeuroCom SMART Balance Master ${ }^{\circledR}$ were used to evaluate changes in postural stability. The Berg Balance Scale was used to evaluate correlations to changes in dynamic balance control. Prior to participation in yoga, significant weight distribution asymmetry was observed during full upright standing. After 8 weeks of yoga training, there were no significant differences in weight distribution between right and left legs at 0 degrees. Subjects demonstrated greater than $50 \%$ improvement in symmetry alignment for different standing positions. No significant changes in compensatory or anticipatory postural adjustments were seen following yoga training. Changes in functional BBS scores were significantly correlated to changes in upright standing symmetry. Yoga training may improve postural symmetry enhancing postural control decreasing the risk for falls in individuals with deficits from chronic stroke.
\end{abstract}

Keywords: Stroke; Yoga; Postural symmetry; Postural adjustment; Functional balance

\section{Introduction}

Annually, approximately 795,000 individuals sustain a stroke in the United States [1]. The high prevalence, negative stroke squeal and the subsequent disability after stroke make it the most commonly treated physical disability by rehabilitation therapists [2]. An important aspect of stroke recovery is the improvement in postural stability or balance. Postural stability has been defined as the ability to control the center of gravity within a given base of support including both static and dynamic conditions [3]. Balance is commonly impaired after stroke and often continues to be impaired into the chronic ( $>6$ months) phases of recovery; [4-10] up to $83 \%$ of individuals demonstrate poststroke balance deficits [11].

Limitations in postural stability after stroke result from lesions in the brain that impact the sensory/motor systems [12,13] and are correlated with: greater physical impairments and disability, decreased ability to perform activities of daily living (ADLs), and increased fall risk [5,11,14-18] Up to $76 \%$ of individuals who have survived a stroke sustain a fall, much more frequently than the healthy elderly, and the elevated fall rate is associated with depression, fractures, and mortality $[5,9,10]$.
Postural stability emerges from a synchronized integration of sensory and motor function [19]. Deficits in motor subsystems that control balance such as postural symmetry and anticipatory and compensatory postural adjustments (APA \& CPA) could negatively impact standing postural stability, increasing the risk of falls [18], decreasing individual confidence with daily activities, and altering the level of social engagement [10]. Standing postural symmetry refers to an individual's ability to maintain an equal distribution of weight over both lower extremities in upright standing [20]. Asymmetry is a common problem following stroke that is associated with hemiparesis $[21,22]$. Standing asymmetry often results in greater weight distribution to the non-paretic limb resulting in paretic limb weakness, instability, and gait abnormalities [22,23].

Altered postural symmetry also decreases the potential for successful balance control when presented with unexpected challenges (i.e. perturbation) [24]. Under perturbation, an individual uses anticipatory and compensatory postural adjustments to control their balance [25]. Anticipatory postural adjustments (APA) are a motor subsystem that function to offset the potential effects on balance control made by planned motor activities [25]. In situations where the individual is aware of the expected balance challenges, the healthy APA system will alter selected patterns of motor recruitment to maintain stability. In contrast, compensatory postural adjustments (CPA) function to maintain balance following unexpected center of mass perturbation [26]. Motor unit recruitment is based upon the required force needed to counter act the displacement of the center of mass 
caused by the disturbance [27]. The more effective APA control creates greater stability and the less need for CPA input [27].

Deficits in motor capacity following stroke poses a potential threat to postural stability in quiet standing; changes in alignment, as well as poor APA and CPA responses, decreases the ability of an individual to accept unexpected balance challenges [24]. Identifying intervention techniques effective at improving symmetrical postural alignment as well as improving APA and CPA postural responses for chronic stroke survivors is imperative. However, at this time, there are no specific evidence-based balance training recommendations for these deficits [4].

In addition, the stroke literature confirms improvement in functional activities when linked to intensive activity specific training environments that are progressive in nature; however, few studies have investigated a focused approach emphasizing balance or the mechanisms of balance control [28]. Thus, there is a need for further development and assessment of progressively challenging interventions focusing on balance training and their potential impact on postural symmetry, anticipatory control, and compensatory mechanism [29].

There is preliminary evidence that yoga may be a progressively challenging exercise intervention that could be used to improve poststroke postural stability [30-33]. The active mind-body connection introduced through a combination of physical postures, breathing, and meditation in yoga may produce different effects considered more beneficial and therapeutic than traditional exercise programs [34-36]. Furthermore, the emphasis on postural alignment and static standing balance control found within yoga training could produce significant changes to individual weight distribution in standing increasing the ability to manage control under perturbation. An emphasis on postural strength and control may also impact the individual's ability to prepare for and react appropriately when challenged by a perturbation. Recently, we studied 47 people with chronic stroke following 8 weeks of group yoga and found significant improvement in functional dynamic balance [33]. The purpose of this study was to assess a subset of individuals for: 1) changes in postural alignment in chronic stroke survivors following yoga training; 2) determine the ability for individuals with chronic stroke deficits to apply APAs and CPAs under perturbation; and 3) measure the change in APAs and CPAs following a yoga training.

\section{Methods}

\section{Design}

This is a secondary analysis from a randomized pilot study [33] measuring clinically applied balance assessments found on the NeuroCom SMART Balance Master ${ }^{\circledR}$ Assessment suite. Individuals with chronic stroke de icits were initially allocated to yoga, a yoga plus home program, and a control group. Subjects randomly assigned to the yoga groups received twice weekly yoga in a group format for 8 weeks (16 sessions). A detailed description of the yoga treatment can be found in the pilot study manuscript [33]. Those individuals assigned to the control group received no intervention. Since no signi icant differences were found between the two treatment groups; yoga data were combined to form one group. Control group participants did not have access to the balance assessments so no comparisons were made. The 8 week yoga training occurred at a university based, integrative therapy lab. Outcome assessments were completed at baseline and immediately following training.

\section{Participants}

The secondary analysis involves a sampling of 21 of the 47 chronic stroke survivors who were allocated to the yoga training groups. Participants were included if they met the following criteria: 18 years and older; sustained a stroke $>6$ months ago; had completed all stroke related rehabilitation; were able to stand with or without a device; scored a $>4$ out of 6 on the short 6 item Mini-Mental State Examination [37] (MMSE); and gave written informed consent to participate. Subject were excluded if they were receiving palliative care, were unable to ensure transportation to the sessions, or had a selfreported medical contraindication (serious cardiac conditions; serious chronic obstructive pulmonary disease or oxygen dependence; severe weight bearing pain; a history of significant psychiatric illness; uncontrollable diabetes with recent weight loss) or current enrollment in another research trial. This study was approved by the Indiana University Institutional Review Board and Veterans Administration Medical Center Research and Development Board. Subjects provided written informed consent prior to participation.

\section{Intervention}

The study intervention consisted of hour-long group yoga sessions twice a week for 8 weeks (16 sessions). A standardized intervention protocol was developed with input from the rehabilitation research team and the yoga therapist. The yoga therapist taught all sessions and the intervention included progressively challenging postures, breathing, and meditation in sitting, standing, and supine positions. There was a focus on balance improvement, thus chosen postures focused on hip and ankle flexibility and strength [38].

\section{Outcome assessments}

Assessments were completed face-to-face by a trained research assistant at baseline and after the 8 week intervention. Self-report of demographics and stroke related characteristics were collected which included: time since stroke; type of stroke (ischemic, hemorrhagic, brainstem, or do not remember); and stroke related disability (Modified Rankin Scale, (mRs). The mRs is a validated measure of the degree of disability and dependence after stroke; $[39,40]$ and defines functional independence with a score of 0-2 (slight to no disability) and dependence as 3-5 (moderate to severe disability) [41,42] Balance measurement was performed on the NeuroCom SMART Balance Master ${ }^{\circledR}$ with safety harnesses to prevent falling to the ground.

\section{Postural stability}

Measures of postural stability were assessed using a computerized dynamic balance measurement, the NeuroCom SMART Balance Master ${ }^{\circledR}$. Postural orientation was measured using the weight bearing squat assessment. This test measured each participant's postural alignment in standing in four conditions with progressively increasing knee flexion. Consistency between subjects for knee position was maintained by goniometric assessment. Quantitative information on postural symmetry was calculated for each position by measuring the percentage of weight distributed through each lower extremity for the four conditions. Improved postural alignment was represented by symmetrical distribution $(50 \% / 50 \%)$ between right and left lower extremities (Table 1). 


\begin{tabular}{|c|c|}
\hline NeuroCom SMART Balance Master As & \\
\hline \multicolumn{2}{|c|}{ Motor Adaptation Test* } \\
\hline Test & Description \\
\hline Toes Up & $\begin{array}{l}\text { Change in force required to control sway during five repeated perturbations where } \\
\text { subject is challenged with backward motion }\end{array}$ \\
\hline Toes Down & $\begin{array}{l}\text { Change in force required to control sway during five repeated perturbations where } \\
\text { subject is challenged with forward motion }\end{array}$ \\
\hline \multicolumn{2}{|c|}{ Weight Bearing Squat Test* } \\
\hline Test Condition & Description \\
\hline Condition $1-0^{\circ}$ of knee flexion (\%) & \multirow{4}{*}{$\begin{array}{l}\text { Measure of the percentage of weight distributed between right and left lower } \\
\text { extremities }\end{array}$} \\
\hline Condition $1-30^{\circ}$ of knee flexion (\%) & \\
\hline Condition $1-60^{\circ}$ of knee flexion (\%) & \\
\hline Condition $1-90^{\circ}$ of knee flexion (\%) & \\
\hline
\end{tabular}

Table 1: Description of the Outcome Measurement Performed on the NeuroCom SMART Balance Master. ${ }^{\star}$ All tests were performed in a standing position.

APAs and CPAs were assessed using the motor adaptation test. The motor adaptation test assesses automatic postural responses, which are dependent on efficient sensory/motor information processing within central nervous system structures. The automatic postural responses were tested through a series of perturbations in the sagittal plane by moving the platform in the following directions: 'toes up' and 'toes down'. The test series was repeated five times in both directions. The amount of force required to recover from the perturbation induced sway was recorded for each trial. The unexpected nature of the initial perturbation establishes a clinical measure of the CPAs invoked to maintain postural alignment. The subject was then aware the same perturbation would be repeated four additional times. Consequently, an intact APA would set the system for an improved response under the second perturbation. The change in response following the initial perturbation would represent the force applied to the static postural position from the APA system providing a clinical measure of APA response. Falls were recorded following perturbation if the subject required a stepping strategy or physical assistance from a researcher was needed to control their balance. Each of the NeuroCom tests is outlined in Table 1 .

\section{Dynamic balance}

Dynamic functional balance was assessed using the Berg Balance Scale (BBS); a 14-item physical performance measure. Previously, we showed balance significantly improved following yoga training for chronic stroke survivors [43]. BBS data are included in this study to assess potential correlations with changes in underlying postural mechanisms.

\section{Statistical Analysis}

Descriptive statistics (means, standard deviations, frequencies, and proportions as appropriate) are included to describe the demographics and stroke characteristics of those individuals included in these analyses. To further describe the sample, a comparison of demographics between those with and without NeuroCom analysis was compared. Normality of data was assessed with the Shapiro-Wilks test. While we did so in the primary paper, we did not carry missing data points forward due to the small sample size and exploratory nature of the present analyses. Data derived from the NeuroCom SMART Balance Master ${ }^{\oplus}$ were compared across the two time points (pretest and following 8 weeks of yoga). Postural symmetry and adaptation were evaluated using paired samples t-tests. Mean scores were evaluated for clinical relevance. Relationships between balance and postural symmetry were evaluated using Pearson correlation.

\section{Results}

Demographic and stroke characteristic data for the entire study cohort $(n=47)$ and those included in these analyses $(n=21)$ are found in Table 2. Baseline demographic or stroke characteristic data were not statistically different for individuals with or without electronic balance assessment (21 vs 26 ) except gender. $43 \%$ of the participants in this secondary analysis were female compared to only $9 \%$ for the overall study. $57 \%$ of the subjects rated themselves independent on the modified Rankin scale.

\section{Mechanisms of Balance Control}

\section{Postural symmetry}

Twenty-one study participants completed balance pre/post balance assessment with the NeuroCom SMART Balance Master ${ }^{\circledast}$. Prior to participation in yoga, significant weight distribution asymmetry $(8 \%$, $\mathrm{p}=0.031$ ) was observed during standing with full knee extension. In addition, a trend towards weight distribution asymmetry was observed with subjects squatting at 60 and 90 degrees $(\mathrm{p}=0.05)$ of knee flexion at baseline (Table 3). After 8 weeks of yoga training, there were no significant differences in weight distribution between right and left legs at 0 degrees. 
Citation: Altenburger PA, Schmid AA, Puymbroeck VM, Miller KK (2016) Impact of Yoga on Postural Stability in Stroke. Int J Neurorehabilitation

Page 4 of 8

\begin{tabular}{|c|c|c|c|c|}
\hline Variable & $\begin{array}{l}\text { Entire Study Sample } \\
(n=47)\end{array}$ & $\begin{array}{l}\text { Computerized } \quad \text { Dynamic } \\
\text { Sample } \\
(\mathrm{n}=21)\end{array}$ & Balance Assessment & $P$ value \\
\hline $\mathrm{Age}^{*}$ & $63.1 \pm 8.8$ & $62 \pm 7.2$ & & 0.419 \\
\hline Race, white & $28(60 \%)$ & $12(57 \%)$ & & 0.760 \\
\hline Female & $9(19 \%)$ & $9(43 \%)$ & & $<0.001$ \\
\hline Time since stroke, months* & $51 \pm 40.4$ & $55.2 \pm 45.3$ & & 0.524 \\
\hline $\begin{array}{l}\text { Type of stroke, self-report Ischemic (versus all other } \\
\text { or unknown) }\end{array}$ & $31(66 \%)$ & $17(81 \%)$ & & 0.07 \\
\hline Disability, independent ${ }^{\star \star}$ & $26(55 \%)$ & $12(57 \%)$ & & 0.821 \\
\hline Quality of Life $(\mathrm{QoL})^{\star \star * *}$ & $33.47+8.49$ & $34.19+9.92$ & & \\
\hline
\end{tabular}

Table 2: Demographic and stroke characteristic data. ${ }^{\star}$ NOTE. Values are mean \pm SD, ${ }^{* *}$ Modified Rankin Scale (mRS), ${ }^{* *}$ Stroke Specific Quality of Life Scale, P values were calculated using Fishers Exact Test for categorical variables and Mann-Whitney U Tests for continuous variables.

\begin{tabular}{|c|c|c|c|c|}
\hline Weight bearing squat variable & Left leg & Right leg & Symmetry Variance & p-value \\
\hline Baseline standing straight up & $46.0 \pm 7.1$ & $54.0 \pm 7.1$ & 8.0 & $.031^{*}$ \\
\hline Baseline 30 degrees of knee flexion & $47.4 \pm 7.6$ & $52.6 \pm 7.6$ & 5.2 & .098 \\
\hline Baseline 60 degrees of knee flexion & $46.9 \pm 7.7$ & $53.0 \pm 7.7$ & 6.1 & .055 \\
\hline Baseline 90 degrees of knee flexion & $46.7 \pm 7.6$ & $53.3 \pm 7.6$ & 6.6 & .054 \\
\hline 8 week standing straight up & $48.6 \pm 7.3$ & $51.7 \pm 7.1$ & 3.1 & .241 \\
\hline 8 week 30 degrees of knee flexion & $49.6 \pm 8.9$ & $50.5 \pm 8.9$ & 0.9 & .708 \\
\hline 8 week 60 degrees of knee flexion & $48.5 \pm 10.5$ & $51.5 \pm 10.5$ & 3.0 & .590 \\
\hline 8 week 90 degrees of knee flexion & $49.1 \pm 9.3$ & $50.9 \pm 9.3$ & 1.8 & .920 \\
\hline
\end{tabular}

Table 3: Measurement of postural symmetry before and after 8 weeks of yoga training. ${ }^{\star}$ Significant difference in weight distribution between right and left side $(\mathrm{p}<.05)$.

Subjects demonstrated greater than $50 \%$ improvement in symmetry alignment for all 4 test positions (Figure 1). A subgroup analysis based on hemiparesis revealed a significant baseline asymmetry in distribution of weight for patients with left hemiparesis at 0,60 , and 90 degrees of knee flexion. Post test results revealed normal weight distributions for all positions within this subgroup, except at 0 degrees.

\section{Postural Adjustment}

Trail 1 of the motor adaptation test was used to assess unexpected perturbation response (CPA); no significant differences were found when comparing mean group forces (lbs.) recruited prior to and following training (Table 4).

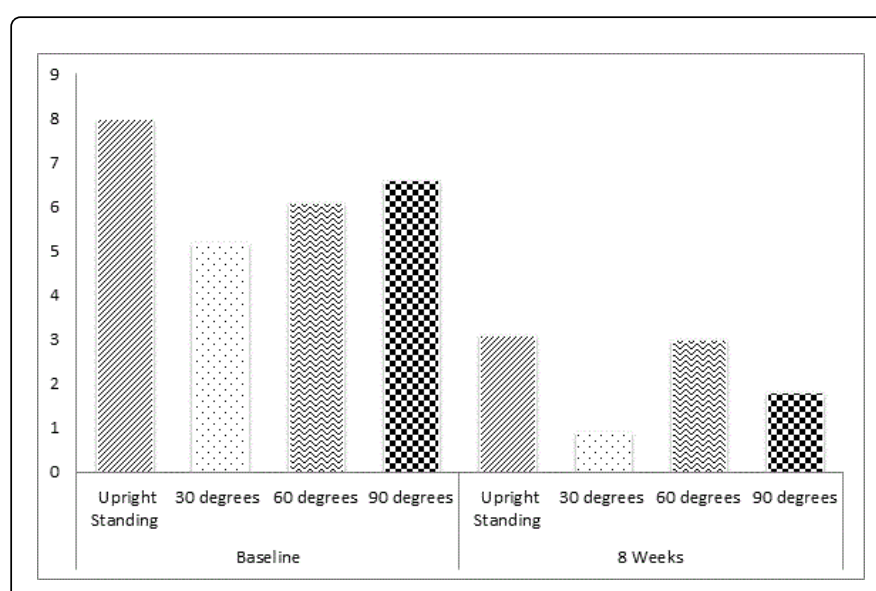

Figure 1: Shows the decrease in postural asymmetry following 8 weeks of yoga training. 
Page 5 of 8

$76 \%$ of individuals were able to control their posture during pretest unpredictable perturbation, following training this number increased to $81 \%$. A decrease in force required to maintain stability in trial 2 when compared to trial 1 was quantified as a measure of APA response effectiveness. Mean change in force recruitment to control perturbation induced sway was compared between the first trial and second trial at pretest and posttest for both toes down (TD) and toes up (TU). No significant difference between pretest and posttest force production was found for either the TD or TU condition (Table 4). Mean scores revealed that on average during the TU condition, more force was recruited to control a posterior center of mass displacement.

\begin{tabular}{|c|c|c|c|c|c|c|}
\hline \multirow{2}{*}{$\begin{array}{l}\text { Variables } \\
\text { Change in Sway } \\
\text { Response (lbs.) }\end{array}$} & \multirow{2}{*}{$\begin{array}{l}\text { Baseline } \\
\text { Trial } 1\end{array}$} & \multirow[b]{2}{*}{ Trial 2} & \multicolumn{2}{|l|}{8 weeks } & \multirow[t]{2}{*}{ p-value ${ }^{*}$} & \multirow[t]{2}{*}{$\mathbf{N}$} \\
\hline & & & Trial 1 & Trial 2 & & \\
\hline \multirow{3}{*}{ Toes Down (TD) } & $52.21 \pm 14.23$ & & $51.35 \pm 15.23$ & & 0.144 & 19 \\
\hline & $52.21 \pm 14.23$ & $47.9 \pm 12.65$ & & & 0.083 & 19 \\
\hline & & & $51.35 \pm 15.23$ & $50.08 \pm 15.09$ & 1 & 20 \\
\hline \multirow{3}{*}{$\begin{array}{l}\text { Toes Up } \\
\text { (TU) }\end{array}$} & $70.50 \pm 16.31$ & & $69.38 \pm 15.84$ & & 0.85 & 17 \\
\hline & $70.50 \pm 16.31$ & $62.68 \pm 16.95$ & & & 0.092 & 17 \\
\hline & & & $69.38 \pm 15.84$ & $64.30 \pm 18.64$ & 0.163 & 18 \\
\hline
\end{tabular}

Table 4: Measurement of change in compensatory and anticipatory postural adjustment. Note: Values are mean $\pm \mathrm{SD}$, ${ }^{\star} \mathrm{P}$ values from Wilcoxon Signed Ranks Test (2 tailed), in values less than 21 were recorded due to falls.

A subset of participants, 7 during TD and 5 during the TU condition, when comparing pretest trial 1 to trial 2 experienced an increase in force production. Post training analysis revealed that $43 \%$ of these subjects in the toes down condition and $60 \%$ in the toes up condition experienced a decrease in force production when comparing trial 2 to trial 1 . Three individuals experienced a fall during initial perturbation (Trial 1) for the TU condition; two of the three also fell during the TD initial trial. Following training, one of the three individuals was able to maintain their initial balance without falling.
Correlational analyses were run evaluating the eight week BBS score with postural symmetry and postural adjustment mechanisms for the 21 subjects (Table 5). Pretest postural assessments demonstrated a significant inverse correlation with the posttest BBS at $0(\mathrm{p}=0.002), 30$ $(\mathrm{p}=0.005)$, and $60(\mathrm{p}=0.006)$ degrees of knee flexion as well as the posttest $0(p=0.026)$ degrees of flexion condition. The BBS change score exhibited a significant positive correlation with the posttest 0 $(\mathrm{r}=0.523, \mathrm{p}=0.015)$ degree knee flexion symmetry score. CPA and APA outcomes were not correlated to BBS posttest outcomes.

\begin{tabular}{|c|c|c|c|}
\hline Berg & Variable of interest & Pearson Correlation, $r$ & p-value \\
\hline \multirow{8}{*}{$\begin{array}{l}8 \text { week Berg Balance Scale } \\
\text { scores }\end{array}$} & Weight bearing squat, $0^{\circ} \mathrm{knee}$ flexion, pretest symmetry variance & -0.638 & $0.002^{*}$ \\
\hline & Weight bearing squat, $30^{\circ}$ knee flexion, pretest symmetry variance & -0.592 & $0.005^{*}$ \\
\hline & Weight bearing squat, $60^{\circ}$ knee flexion, pretest symmetry variance & -0.576 & $0.006^{*}$ \\
\hline & Weight bearing squat, $90^{\circ}$ knee flexion, pretest symmetry variance & -0.288 & 0.205 \\
\hline & Weight bearing squat, $0^{\circ}$ knee flexion, posttest symmetry variance & -0.483 & $0.026^{*}$ \\
\hline & Weight bearing squat, $30^{\circ}$ knee flexion, posttest symmetry variance & -0.312 & 0.169 \\
\hline & Weight bearing squat, $60^{\circ}$ knee flexion, posttest symmetry variance & -0.221 & 0.336 \\
\hline & Weight bearing squat, $90^{\circ}$ knee flexion, posttest symmetry variance & -0.332 & 0.141 \\
\hline $\begin{array}{l}\text { Pre/Post Berg Balance } \\
\text { Change Score }\end{array}$ & Weight bearing squat, $0^{\circ}$ knee flexion, posttest symmetry variance & 0.523 & $0.015^{\star}$ \\
\hline
\end{tabular}

Table 5: Correlation table for Berg balance scale scores.

\section{Discussion}

With this study, we attempted to determine the impact of yoga treatment on postural stability mechanisms in individuals with chronic stroke deficits. Yoga treatment focuses on the awareness of the individual's body alignment and orientation while performing different postures. In addition, participants were asked to actively engage in relaxation while working through directed postural control activities. 
Based upon the mechanisms of the treatment approach, it was hypothesized that participants in this study would experience positive changes in both postural symmetry and adjustment.

\section{Postural symmetry}

Individuals with chronic stroke deficits in this study exhibited significantly deviated postural alignment in upright standing prior to training. Following yoga, postural asymmetry was reduced by as much as $80 \%$ for some individuals. Previous studies have indicated that asymmetrical alignment contributes to impaired balance and decreased ambulatory ability [44]. Limitations in both balance and gait speed have been correlated with deficits in social participation [45]. Although participants in this study were in a chronic state of recovery, training with yoga based therapy demonstrated an ability to alter motor strategies resulting in more equalized postural distribution. These findings suggest it is possible with training for an individual in a chronic state of recovery to alter their postural symmetry.

Functional balance measurement using the BBS was found to be inversely related to asymmetry measures prior to and following training in upright standing. Higher posttest BBS scores were related to decreases in asymmetrical alignment. Specifically, $23 \%$ of the variance in the BBS posttest score could be explained by posttest upright symmetrical alignment. Postural orientation as measured by symmetry seems to play a role in functional balance stability. A similar finding looking at gait parameters was found by Hendrickson et al. [23].

\section{Postural adjustments}

To avoid falling, an individual must compensate for unexpected challenges and adjust to further expected perturbations. Prior to training in this study, a majority $(76 \%)$ of the subjects demonstrated compensatory postural activation to overcome unpredictable challenges to standing postural stability. The ability of individuals to maintain balance while challenged with unexpected center of mass translation both anterior and posterior is encouraging. CPAs are needed to avoid falling in static and dynamic conditions. Following yoga training, the average amount of force recruited to maintain balance under either condition did not significantly change. This, in part, might be attributed to the effective application of CPA mechanism prior to training. In addition, yoga training does involve a task specific training paradigm that would like impact CPA control. Two individuals, who fell during CPA pre-testing, demonstrated an ability to maintain upright balance control at posttest. The improvement in CPA effectiveness is clinically relevant as it suggests these two individuals following training may be more likely to withstand an unexpected challenging preventing a fall. Postural training focusing on orientation and upright control appeared to improve these individuals' ability to control balance during unexpected challenges.

Participants in this study also exhibited the ability to make effective anticipatory adjustments to their postural control mechanisms prior to the start of the study. This result is also encouraging considering that many of the subjects reported limited activity levels. While overall changes in APA activity were not significant following training, responses did show improvement for several individuals who initially exhibited ineffective APA response (increased force production) during trial 2 of the pretest. This finding suggests the possibility for an individual to improve anticipatory postural adjustments control with training. Changes in CPA and APA mechanism were not found to be correlated to the BBS. The BBS measures deliberate dynamic functional movements while the postural adjustment tests look at perturbation management; the differences may account for the lack of clinical correlation. In addition, CPA and APA mechanisms are governed by automatic, unconscious motor pathways while dynamic balance activities within the BBS are predominately controlled by volitional motor pathways. The difference in neurological control may also account for the limited connection.

\section{Clinical relevance}

Limitations in postural alignment and adjustment predispose an individual to balance control and increase risk for falls. Yoga training provides a task specific approach focusing on the awareness of postural alignment and symmetry as it relates to each pose. The emphasis on postural awareness and control has been shown to be effective in enhancing balance control in previous studies [46]. The translation of this training resulted in significant improvement in postural alignment that was related to functional balance outcomes in upright standing. A potential advantage is the ability to translate this approach to a home/ lifestyle program. Yoga represents a therapeutic approach that could be integrated into daily life that often does not occur with more traditional therapeutic exercise home programs. The opportunity to develop a consistent training program could significantly limit postural atrophy, decreasing fall risk and medical necessity. Research evidence supports a link between alignment and dynamic balance and gait. Maintaining strong postural symmetry could provide a key foundation for continued functional independence and societal participation. The lack of correlation between dynamic balance and postural adjustments suggests the need for developing task specific training for both mechanisms since training in one paradigm is not likely to translate to improvements in the other.

\section{Limitations}

Limitations of this study include: unblinded outcome assessment; small sample size (reduced from parent study due to less people completing NeuroCom balance assessment); all participants are from the same urban area; all participants had to be able to access the university campus, thus individuals not able to drive or use public transportation were excluded. Yoga based postural stability exercises used within this treatment regimen were not task specific for dynamic motor capacity. Further dosing and positional selection that would match the intensity requirements for motor capacity improvement may need to be explored.

\section{Conclusion}

The results indicate that yoga is likely a viable option as a complement to rehabilitation and recovery after stroke for improvements in postural stability. Specifically, yoga had a positive influence for this cohort on postural symmetry, which is a foundational building block for more dynamic movement capacity. Yoga training should be further explored in a large randomized controlled trial to better understand the potential impact. The longterm impact of consistently applied home programming is worth exploring to determine an impact on ambulatory ability and functional independence. 


\section{Acknowledgement}

Clinical Trial Registration Information: URL: http:// www.clinicaltrials.gov, NCT01109602.

\section{Funding}

This project was supported by VA-QUERI-RRP: 09-095. Dr. Schmid was supported by VA RR\&D CDA D6174W.

\section{References}

1. Lloyd-Jones D, Adams RJ, Brown TM, Carnethon M, et al. (2010) Heart disease and stroke statistics--2010 update: a report from the American Heart Association. Circulation 121: e46-46e215.

2. Pulaski K (2003) Adult neurological dysfunction. In: Crepeau EBCE, Schell BAB (eds.) Willard and Spackman's occupational therapy, Philadelphia: Lippincott, Williams and Wilkins pp: 767-788.

3. Shumway-Cook A, Woollacott M (2001) Motor control: Theory and practical application. Philadelphia, Lippincott Williams and Wilkins.

4. Duncan PW, Zorowitz R, Bates B, Choi JY, Glasberg JJ, Graham GD, et al. (2005) Management of adult stroke rehabilitation care: A clinical practice guideline. Stroke: A journal of cerebral circulation 36: e100-143.

5. Forster A, Young J (1995) Incidence and consequences of falls due to stroke: a systematic inquiry. BMJ 311: 83-86.

6. Schmid AA, Rittman M (2009) Consequences of poststroke falls: activity limitation, increased dependence, and the development of fear of falling. Am J Occup Ther 63: 310-316.

7. Schmid AA, Rittman M (2007) Fear of falling: an emerging issue after stroke. Top Stroke Rehabil 14: 46-55.

8. Yates JS, Lai SM, Duncan PW, Studenski S (2002) Falls in communitydwelling stroke survivors: An accumulated impairments model. Journal of rehabilitation research and development 39: 385-394.

9. Jørgensen L, Engstad T, Jacobsen BK (2002) Higher incidence of falls in long-term stroke survivors than in population controls: depressive symptoms predict falls after stroke. Stroke 33: 542-547.

10. Schmid AA, Van Puymbroeck M, Altenburger PA, Miller KK, Combs SA, et al. (2013) Balance is associated with quality of life in chronic stroke. Top Stroke Rehabil 20: 340-346.

11. Tyson SF, Hanley M, Chillala J, Selley A, Tallis RC (2006) Balance disability after stroke. Phys Ther 86: 30-38.

12. Michael KM, Allen JK, Macko RF (2005) Reduced ambulatory activity after stroke: the role of balance, gait, and cardiovascular fitness. Arch Phys Med Rehabil 86: 1552-1556.

13. Rogers MW, Martinez KM (2009) Recovery and rehabiliation of standing balance after stroke. In: Stein J, Harvey RL, Macko RF, Winstein C, Zorowitz RD (eds.) Stroke recovery and rehabilitation, Demos medical: evidence, New York.

14. Sackley CM, Baguley BI, Gent S, Hodgson P (1992) The use of a balance performance monitor in the treatment of weight-bearing and weighttransference problems after stroke. Physiotherapy. 78: 907-913.

15. Hyndman D, Ashburn A, Stack E (2002) Fall events among people with stroke living in the community: circumstances of falls and characteristics of fallers. Arch Phys Med Rehabil 83: 165-170.

16. Harris JE, Eng JJ, Marigold DS, Tokuno CD, Louis CL (2005) Relationship of balance and mobility to fall incidence in people with chronic stroke. Phys Ther 85: 150-158.

17. Belgen B, Beninato M, Sullivan PE, Narielwalla K (2006) The association of balance capacity and falls self-efficacy with history of falling in community-dwelling people with chronic stroke. Arch Phys Med Rehabil 87: 554-561.

18. Ikai T, Kamikubo T, Takehara I, Nishi M, Miyano S (2003) Dynamic postural control in patients with hemiparesis. American journal of physical medicine and rehabilitation / Association of Academic Physiatrists 82:463-469.
19. de Haart M, Geurts AC, Huidekoper SC, Fasotti L, van Limbeek J (2004) Recovery of standing balance in postacute stroke patients: a rehabilitation cohort study. Arch Phys Med Rehabil 85: 886-895.

20. Leroux A, Pinet H, Nadeau S (2006) Task-oriented intervention in chronic stroke: Changes in clinical and laboratory measures of balance and mobility. American journal of physical medicine \& rehabilitation / Association of Academic Physiatrists 85: 820-830.

21. Genthon N, Gissot AS, Froger J, Rougier P, Perennou D (2008) Posturography in patients with stroke: Estimating the percentage of body weight on each foot from a single force platform. Stroke: A journal of cerebral circulation 39: 489.

22. Bohannon RW, Larkin PA (1985) Lower extremity weight bearing under various standing conditions in independently ambulatory patients with hemiparesis. Phys Ther 65: 1323-1325.

23. Hendrickson J, Patterson KK, Inness EL, Mcllroy WE, Mansfield A (2014) Relationship between asymmetry of quiet standing balance control and walking post-stroke. Gait Posture 39: 177-181.

24. Garland SJ, Stevenson TJ, Ivanova T (1997) Postural responses to unilateral arm perturbation in young, elderly, and hemiplegic subjects. Arch Phys Med Rehabil 78: 1072-1077.

25. Kanekar N, Aruin AS (2014) The effect of aging on anticipatory postural control. Exp Brain Res 232: 1127-1136.

26. Alexandrov AV, Frolov AA, Horak FB, Carlson-Kuhta P, Park S (2005) Feedback equilibrium control during human standing. Biol Cybern 93: 309-322.

27. Santos MJ, Kanekar N, Aruin AS (2010) The role of anticipatory postural adjustments in compensatory control of posture: Electromyographic analysis. J Electromyogr Kinesiol 20: 388-397.

28. An M, Shaughnessy M (2011) The effects of exercise-based rehabilitation on balance and gait for stroke patients: a systematic review. J Neurosci Nurs 43: 298-307.

29. Lubetzky-Vilnai A, Kartin D (2010) The effect of balance training on balance performance in individuals poststroke: A systematic review. J Neurol Phys Ther 34: 127-137.

30. Garrett R, Immink MA, Hillier S (2011) Becoming connected: the lived experience of yoga participation after stroke. Disabil Rehabil 33: 2404-2415.

31. Bastille JV, Gill-Body KM (2004) A yoga-based exercise program for people with chronic poststroke hemiparesis. Phys Ther 84: 33-48.

32. Lynton H, Kligler B, Shiflett S (2007) Yoga in stroke rehabilitation: a systematic review and results of a pilot study. Top Stroke Rehabil 14: 1-8.

33. Schmid AA, Van Puymbroeck M, Altenburger PA, Schalk NL, Dierks TA, et al. (2012) Poststroke balance improves with yoga: a pilot study. Stroke 43: 2402-2407.

34. Brown DR, Wang Y, Ward A, Ebbeling CB, Fortlage L, et al. (1995) Chronic psychological effects of exercise and exercise plus cognitive strategies. Med Sci Sports Exerc 27: 765-775.

35. Kirkwood G, Rampes H, Tuffrey V, Richardson J, Pilkington K (2005) Yoga for anxiety: a systematic review of the research evidence. Br J Sports Med 39: 884-891.

36. Cameron M (2006) Yoga. In: Snyder M, Lindquist $R$ (eds.) Complementary/alternative therapies in nursing, Springer Publishing Company, Inc, New York, NY.

37. Callahan CM, Unverzagt FW, Hui SL, Perkins AJ, Hendrie HC (2002) Sixitem screener to identify cognitive impairment among potential subjects for clinical research. Med Care 40: 771-781.

38. Chiacchiero M, Dresely B, Silva U, DeLosReyes R, Vorik B (2010) The relationship between range of movement, flexibility and balance in the elderly. Topics in Geriatric Rehabilitation 26: 148-155.

39. Lindley RI, Waddel F, Livingstone M (1994) Can simple questions assess outcomes after stroke. Cerebrovasc Dis. 4: 314-324.

40. Rankin J (1957) Cerebral vascular accidents in patients over the age of 60 . III. Diagnosis and treatment. Scott Med J 2: 254-268. 
Citation: Altenburger PA, Schmid AA, Puymbroeck VM, Miller KK (2016) Impact of Yoga on Postural Stability in Stroke. Int J Neurorehabilitation 3: 195. doi:10.4172/2376-0281.1000195

Page 8 of 8

41. Schmid AA, Kroenke K, Hendrie HC, Bakas T, Sutherland JM, et al (2011) Poststroke depression and treatment effects on functional outcomes. Neurology 76: 1000-1005.

42. Sulter G, Steen C, De Keyser J (1999) Use of the Barthel index and modified Rankin scale in acute stroke trials. Stroke 30: 1538-1541.

43. Berg K, Wood-Dauphinee S, Williams JI (1995) The Balance Scale: reliability assessment with elderly residents and patients with an acute stroke. Scand J Rehabil Med 27: 27-36.

44. Aruin AS (2006) The effect of asymmetry of posture on anticipatory postural adjustments. Neurosci Lett 401: 150-153.
45. Schmid AA, Van Puymbroeck M, Altenburger PA, Dierks TA, Miller KK, et al. (2012) Balance and balance self-efficacy are associated with activity and participation after stroke: a cross-sectional study in people with chronic stroke. Arch Phys Med Rehabil 93: 1101-1107.

46. Bayouk JF, Boucher JP, Leroux A (2006) Balance training following stroke: effects of task-oriented exercises with and without altered sensory input. Int J Rehabil Res 29: 51-59. 